Article

\title{
Fabrication and Analysis of a Ti6Al4V Implant for Cranial Restoration
}

\author{
Khaja Moiduddin*(D), Syed Hammad Mian ${ }^{\mathbb{D}}$, Usama Umer ${ }^{\mathbb{D}}$ and Hisham Alkhalefah
}

Advanced Manufacturing Institute, King Saud University, Riyadh 11421, Saudi Arabia;

syedhammad68@yahoo.co.in (S.H.M.); usamaumer@yahoo.com (U.U.); halkhalefah@ksu.edu.sa (H.A.)

* Correspondence: kmoiduddin@gmail.com or Khussain1@ksu.edu.sa

Received: 25 May 2019; Accepted: 18 June 2019; Published: 20 June 2019

Abstract: A custom made implant is critical in cranioplasty to cushion and restore intracranial anatomy, as well as to recover the appearance and attain cognitive stability in the patient. The utilization of customized titanium alloy implants using three-dimensional (3D) reconstruction technique and fabricated using Electron Beam Melting (EBM) has gained significant recognition in recent years, owing to their convenience and effectiveness. Besides, the conventional technique or the extant practice of transforming the standard plates is unreliable, arduous and tedious. As a result, this work aims to produce a customized cranial implant using 3D reconstruction that is reliable in terms of fitting accuracy, appearance, mechanical strength, and consistent material composition. A well-defined methodology initiating from EBM fabrication to final validation has been outlined in this work. The custom design of the implant was carried out by mirror reconstruction of the skull's defective region, acquired through computer tomography. The design of the customized implant was then analyzed for mechanical stresses by applying finite element analysis. Consequently, the 3 D model of the implant was fabricated from Ti6Al4V ELI powder with a thickness of $\simeq 1.76-2 \mathrm{~mm}$. Different tests were employed to evaluate the bio-mechanical stability and strength of the fabricated customized implant design. A 3D comparison study was performed to ensure there was anatomical accuracy, as well as to maintain gratifying aesthetics. The bio-mechanical analysis results revealed that the maximum Von Mises stress $(2.5 \mathrm{MPa})$, strain distribution $\left(1.49 \times 10^{-4}\right)$ and deformation $\left(3.26 \times 10^{-6} \mathrm{~mm}\right)$ were significantly low in magnitude, thus proving the implant load resistance ability. The average yield and tensile strengths for the fabricated Ti6Al4V ELI EBM specimen were found to be $825 \mathrm{MPa}$ and $880 \mathrm{MPa}$, respectively, which were well over the prescribed strength for Ti6Al4V ELI implant material. The hardness study also resulted in an acceptable outcome within the acceptable range of 30-35 HRC. Certainly, the chemical composition of the fabricated EBM specimen was intact as established in EDX analysis. The weight of the cranial implant (128 grams) was also in agreement with substituted defected bone portion, ruling out any stress shielding effect. With the proposed approach, the anatomy of the cranium deformities can be retrieved effectively and efficiently. The implementation of 3D reconstruction techniques can conveniently reduce tedious alterations in the implant design and subsequent errors. It can be a valuable and reliable approach to enhance implant fitting, stability, and strength.

Keywords: cranial restoration; electron beam melting; custom-made implant; 3D comparison; tensile strength; mirror reconstruction; rockwell hardness

\section{Introduction}

Cranial restoration or cranial defect replacement can be defined as a medical procedure to reinstate an unhealthy or damaged region on the skull [1]. The primary objective is the shielding of tissues and nerves within the skull, along with the realization of body shape and the achievement of mental 
stability in the patient [2]. Cranial restoration is generally carried out on patients who suffer from head trauma as a result of any injury (accident), infection or congenital deformities [3]. The skull injuries or malformation are considered as one of the most critical and worrying health concerns, which affects a large population all over the world [4]. Moreover, the repairing of cranial abnormalities poses serious challenges, even to experienced surgeons, because the body part being operated on comprises of nerves, soft tissues, or other delicate organs, inside a confined zone [5]. A variety of different approaches, such as autologous bone grafting [6,7], utilization of standard implants manufactured from traditional methods, like casting, forging, machining and powder metallurgy techniques [8,9], etc., were the common techniques in cranial restoration. However, in recent times, the application of these approaches has been minimized owing to their compelling drawbacks. For example, the autologous bone grafting technique involves complicated operative methods, blood loss, and pain in the patient, etc., [10]. Similarly, the employment of regular implants, which necessitates physical bending or rearrangement using trial runs to custom fit the patient bone contour, is a time-consuming, inaccurate, and laborious approach [11]. Furthermore, any discrepancy would result in implant failure, a greater number of amendments and psychological stress on the patient's mind. Henceforth, to minimize disparities and conform bone contours as well as provide enhanced cosmetic output, it is imperative to make use of the concept of customized implant design $[12,13]$. The customized design of an implant can improve fitting accuracy significantly and reduces the operation time in contrast to standard plates.

The rapidly growing health care demands owing to aging, expanding the global population, etc., emphasize the importance of innovative technologies in the medical field. The unification of medical data imaging, image processing software and additive manufacturing (AM) has the potential to produce any complex structure (customized implant) with a perfect fit, which can match the bone contour and result in a trimmed appearance. The implementation of integrated techniques can save a huge cost for health systems in addition to improving the quality of life for a large population [14]. A favorable outcome in implant reconstruction depends on several factors such as the material characteristics, implant design, fabrication method and skills of the surgeon. Certainly, the design of customized implants must conform to the individual patient's needs, inclusive of the size, shape and mechanical properties of the implant. As a consequence of unique human anatomy, AM is very useful to accomplish patient-specific implants, matching the bone contours with a perfect fit. The AM has significantly upgraded the ability to manufacture intricate geometrical structures with precision in comparison to the conventional processing methods [15]. It can produce sufficiently packed and graded structures with appropriate accuracy and process adaptability. The applications of AM, especially in the medical sector, have been increasing very quickly and are expected to revolutionize the health care sector. It can successfully manage the requirements of medical devices, in terms of product customization, efficient and cost-effective production, short delivery time, etc. In addition to the appropriate fabrication approach, the precise and pertinent requirements of customized implants also necessitate the implementation of relevant bio-materials. Out of the possible metallic materials that can be usedTitanium Alloy (Ti6Al4V) is considered as the most favored choice for the customized implants. This can be attributed to its biological compatibility, Osseo-integrative property, high strength to weight ratio, higher corrosion resistance, non-magnetic properties, high toughness, and mechanical resistance, etc., [16-18].

There are a multitude of different kinds of AM technologies in the market, but all of them follow the same principle of manufacturing three-dimensional (3D) objects from computer-aided design (CAD) models by depositing the raw material in a layer by layer manner. The various AM technologies available in the market are stereolithography (SLA), fused deposition modeling (FDM), selective laser sintering (SLS), 3D printing (3DP), Electron Beam Melting (EBM), etc. These systems can be categorized depending on the bulk material (or the original state of the raw material), which can be liquid, solid or powder [19-21]. The AM technology employed in this work is EBM in order to fabricate the customized implant. One of the primary strengths of EBM is its ability to produce parts from titanium alloys (Ti6Al4V). EBM has been widely utilized in the production of medical implants throughout Europe and 
the United States with a Food and Drug Administration (FDA) license [22]. It was initially marketed in 1997 by ARCAM AB Corporation, Sweden which has acquired more than thirty international patents involving EBM science or techniques [23]. The earlier studies have suggested EBM as a rational option for titanium alloy custom designed implants required in orthopedic, craniofacial and maxillofacial surgeries [24-26]. Unlike other traditional methods, EBM does not possess any limitation in terms of shape constraints and can produce complicated parts with nearly perfect accuracy. Indeed, the titanium alloy (Ti6Al4V ELI) used in the current EBM process has proven to have good mechanical and chemical properties for implants [27,28].

In this paper, a comprehensive approach for the design, fabrication, and validation of a customized cranial implant has been developed. The primary goal of this study is the introduction of a simple method to redesign and fabricate the defective part on the skull. The AM has been combined with digital image acquisition techniques, like computed tomography (CT) to achieve the mentioned objective. This work demonstrates the route from the patient's CT scan to the fabrication of titanium cranial implants and its validation. The DICOM (digital imaging and communication in medicine) files from CT were imported in a specific software (Mimics) and the segmentation approach was employed to cut the region of interest and produce the 3D model. The mirror reconstruction technique was utilized to generate the patient-specific implant on the injured portion of the skull. This design was then analyzed and compared with the cortical bone for mechanical properties through finite element analysis (FEA). Subsequently, the titanium cranial implant $(\simeq 1.76-2 \mathrm{~mm}$ thick) was fabricated from Ti6Al4V ELI powder by using EBM technology. It was finally validated and investigated for appearance, accuracy, mechanical properties, and material composition.

\section{Methodology}

The proposed methodology for acquiring a customized cranial implant has been based on four major pillars, including image processing, modeling, fabrication, and testing. The work-flow from data acquisition to final testing can be realized in Figure 1. The approach is exhaustive, comprising of numerous sub-procedures, such as segmentation, Standard Tessellation Language (STL) error correction, thickness reduction, etc., to ensure a dependable cranial implant. The discussion about the different steps in the methodology is presented in the following sections.

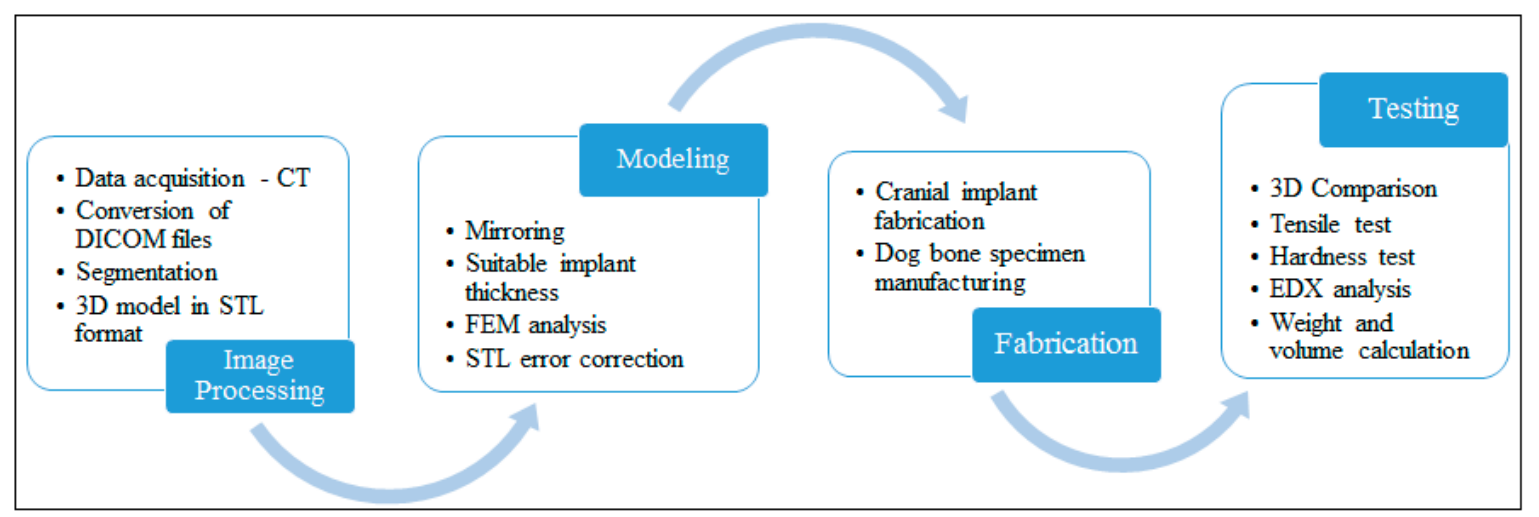

Figure 1. Methodology to obtain a customized cranial implant.

\subsection{Image Processing}

A cranial defect case from the University Hospital was selected to employ the proposed approach. To begin with, CT scanning of a thirty-year-old patient suffering from a sizable cranial deformity in the left parieto-temporal area was carried out. The CT data were captured by using a ProMax 3D Cone Beam CT machine (Planmeca, Helsinki, Finland). The gathered images were stored as DICOM files. These DICOM files consisted of 2D layers from all-around (front, side and back ends) the patient's cranium. A well-known medical image processing software which is known as Mimics $17.0^{\circledR}$ 
(Materialize NV, Belgium), was utilized to transform the acquired DICOM files in the quintessential 3D model.

The 3D model is useful because it includes information about the patient's bones, skin, soft tissues, etc. To access the area of interest as well as to divide the hard and soft tissues, segmentation and region growing techniques were exploited in Mimicsß. Figure 2 depicts the various steps of surface modeling from a fully scanned skull model to the region of interest. The segmentation was accomplished through the identification of image intensities in Hounsfield units (HU). The HU was used because it could quantify the attenuation coefficient of different regions in CT scan images and provided the right type of tissues. For example, bone exhibits a higher HU value in contrast to skin and soft tissues owing to its ability to absorb a greater amount of radiation. The region growing algorithm was required to minimize or remove any noise, outlier or gap in the image data, thus providing a continuous set of pixels as shown in Figure 2a. A 3D rendered model of the patient's cranium was obtained as shown in Figure $2 \mathrm{~b}$ by exploiting the reconstruction tool. The 3D surface modeling is a tiresome and tardy procedure because it has to be reworked numerous times until the desired region of interest (affected area) is realized. The finally obtained region of interest, a 3D skull model without the neck region (Figure 2 $\mathrm{c}^{\prime}$ ), was stored in the STL format for the subsequent implant modeling process.

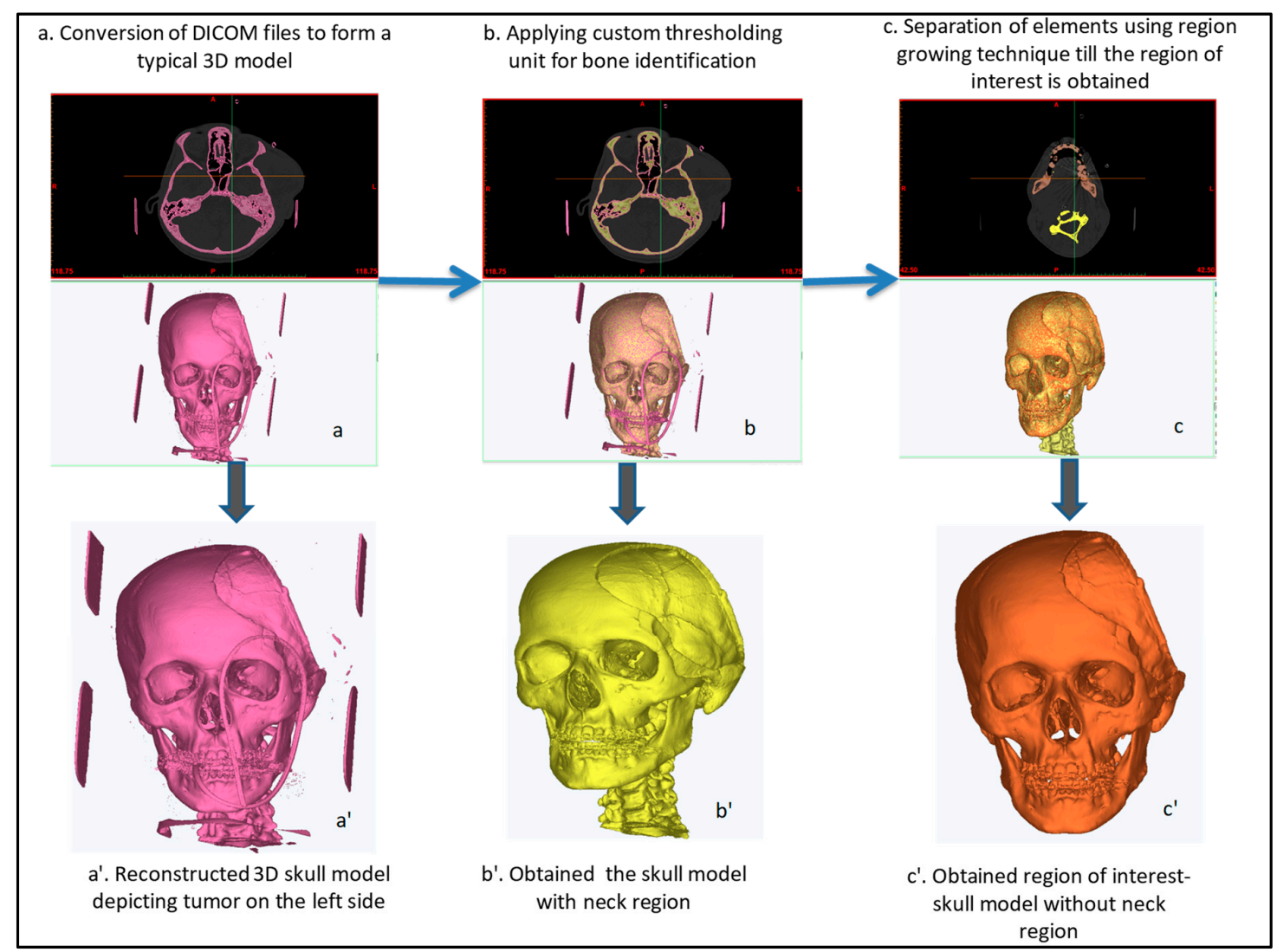

Figure 2. Image processing stages in Mimics ${ }^{\circledR}$ : (a) Coversion of DICOM files; (a') Reconstructed 3D skull model; (b) Bone identification; (b') Skull model with neck region; (c) Application of region growing technique; $\left(\mathbf{c}^{\prime}\right)$ Obtaining region of interest.

\subsection{Modeling}

The main objective of this step was the designing of a customized cranial implant through the mirroring technique. Certainly, the mirror reconstruction technique can be identified as an influential and most extensively employed implant design technique in medical restorative applications, especially in animal anatomy where bi-lateral symmetry prevails [28]. It can also be established here that the anatomical structures acquired through mirroring are practically ideal and optimal $[29,30]$. 
The modeling stage commenced with the importing of 3D model's STL file (Figure 3a) in 3-Matic 9.0 ${ }^{\circledR}$ (Materialize NV, Belgium) software. The following workflow adopted to accomplish the mirroring which assumed human anatomy to be symmetric.

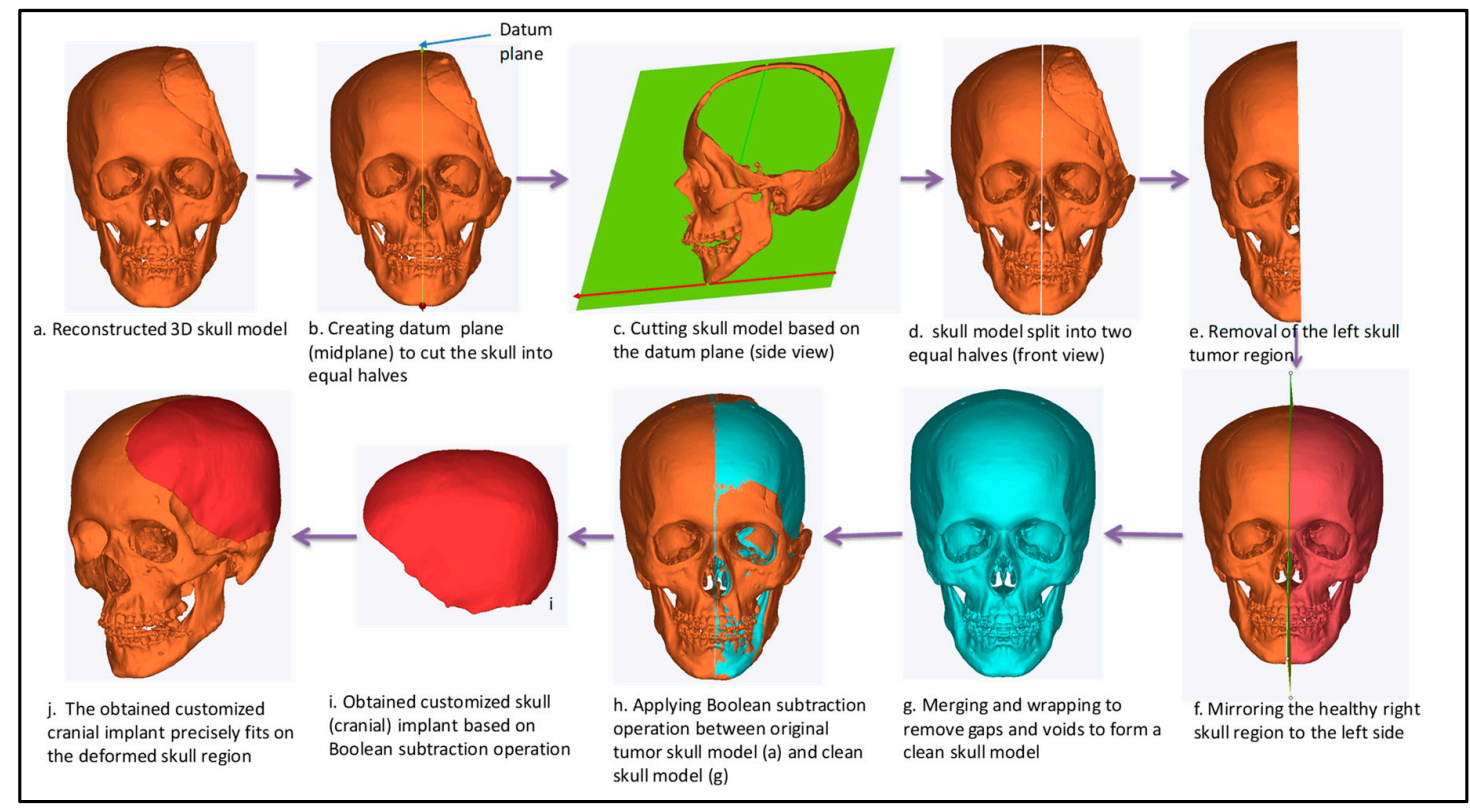

Figure 3. Steps involved in the design of customized cranial implant in 3-Matic ${ }^{\circledR}$ : (a) Reconstruction of 3D skull model; (b) Generation of midplane; (c) Cutting of skull model; (d) Splitted model; (e) Removal of defected side; (f) Mirroring of right side; (g) Merging of two sides; (h) Application of Boolean subtraction; (i) Customized implant; (j) Skull with fitted Implant.

- The cranium was segregated through datum plane (mid-plane) after determining two maximal endpoints (Figure 3b,c).

- The deformed or the deficient left side was taken out through the cutting operation (Figure 3d,e).

- The normal or healthy bone on the contralateral side was imitated with reference across the center plane (or symmetric plane) (Figure 3f).

- Merging and wrapping operations were carried out to minimize the disparities, inconsistencies and discontinuous surfaces between them (Figure 3g).

- Consequently, a Boolean subtraction procedure (Figure 3h) was executed among the freshly designed skull model (Figure 3g) and the original skull containing defect (Figure 3a).

- The mirroring procedure generated the tailored cranial implant (Figure 3i) with a thickness of $\simeq 5.76 \mathrm{~mm}$ (thickness of the cranial bone).

The mirrored model assured a simple and precise fitting through the edge of the defective region as well, as it resulted in an implant contour which was perfect in terms of aesthetics and appearance. An impeccable alignment of the newly designed personalized cranial implant (red area) adjacent to the defective skull region (orange region) can be seen in Figure 4. 


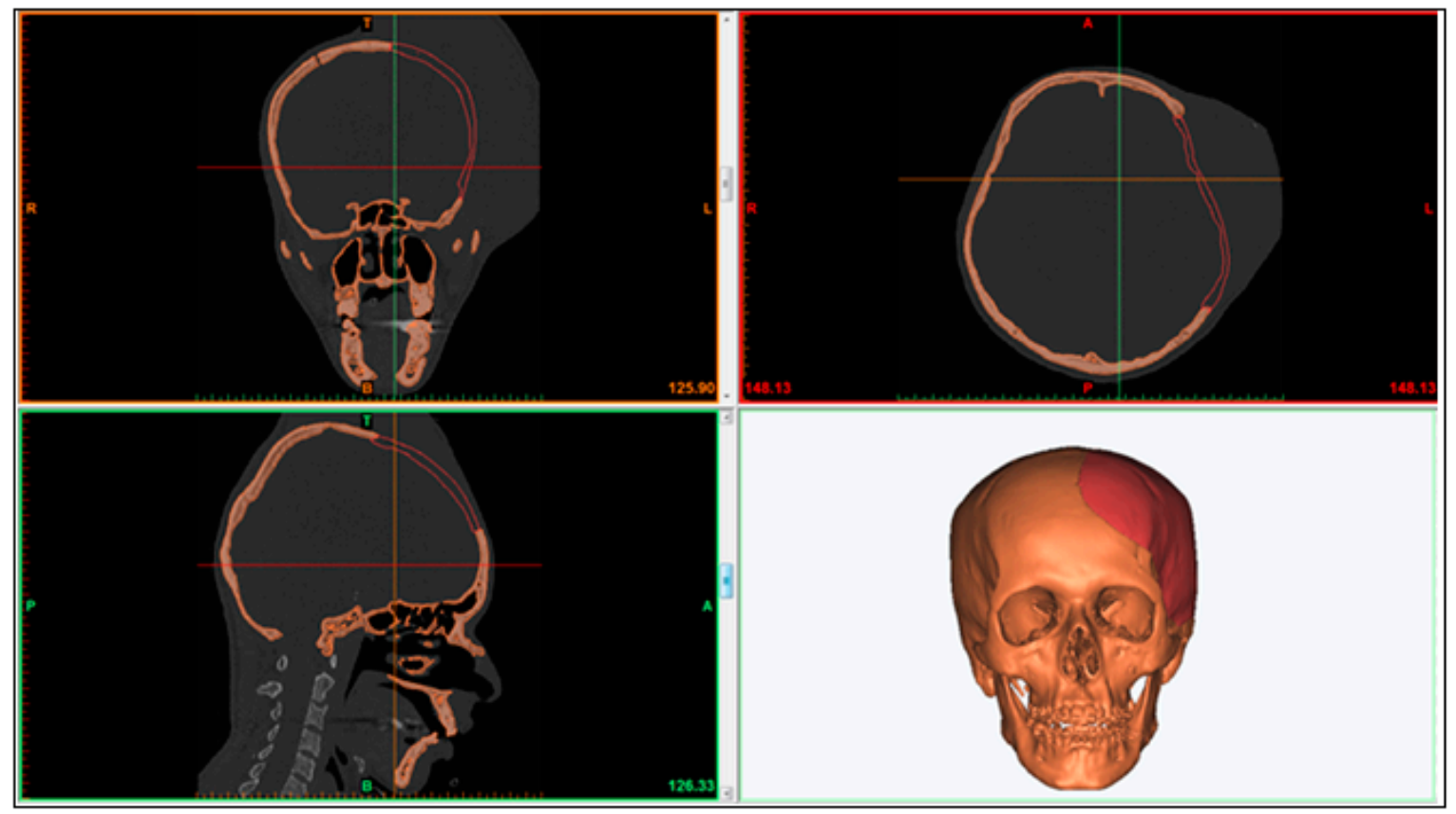

Figure 4. Precise fitting of custom built cranial implant on the deformed skull region.

As a result of redundant implant thickness, the likelihood of the stress shielding effect across the surrounding bone also increased. Therefore, to minimize the thickness and weight of the implant nearer to the bone counterpart, an offset operation was implemented on the thick cranial implant (Figure 5a,b). Finally, an implant with a thickness in the range of $\simeq 1.76-2 \mathrm{~mm}$ was obtained, as shown in Figure 5c.

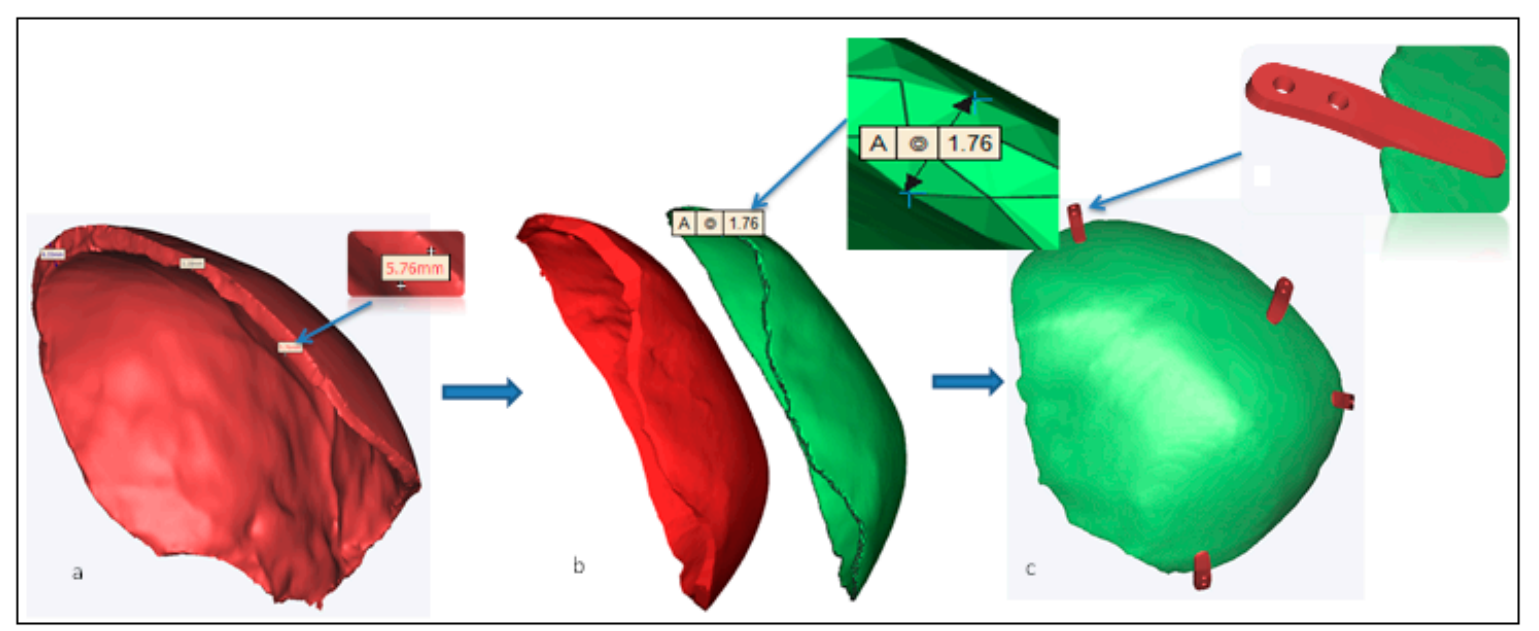

Figure 5. Thickness minimization and mini-plates attachment for fixing of screws: (a) Actual thickness; (b) Reduced thickness; (c) Implant fitted with mini-sheets.

Moreover, the quadruple fixation mini-sheets with taper screw holes were also designed as shown in Figure 6a. They were needed to achieve the stability, sturdy connection and fixation of the implant on to the cranium as shown in Figure $6 \mathrm{~b}$. The tapered designed screw holes as a result of the entire sinking of the screws aided in the stability and rigidity as well as improving the patient's comfort. 


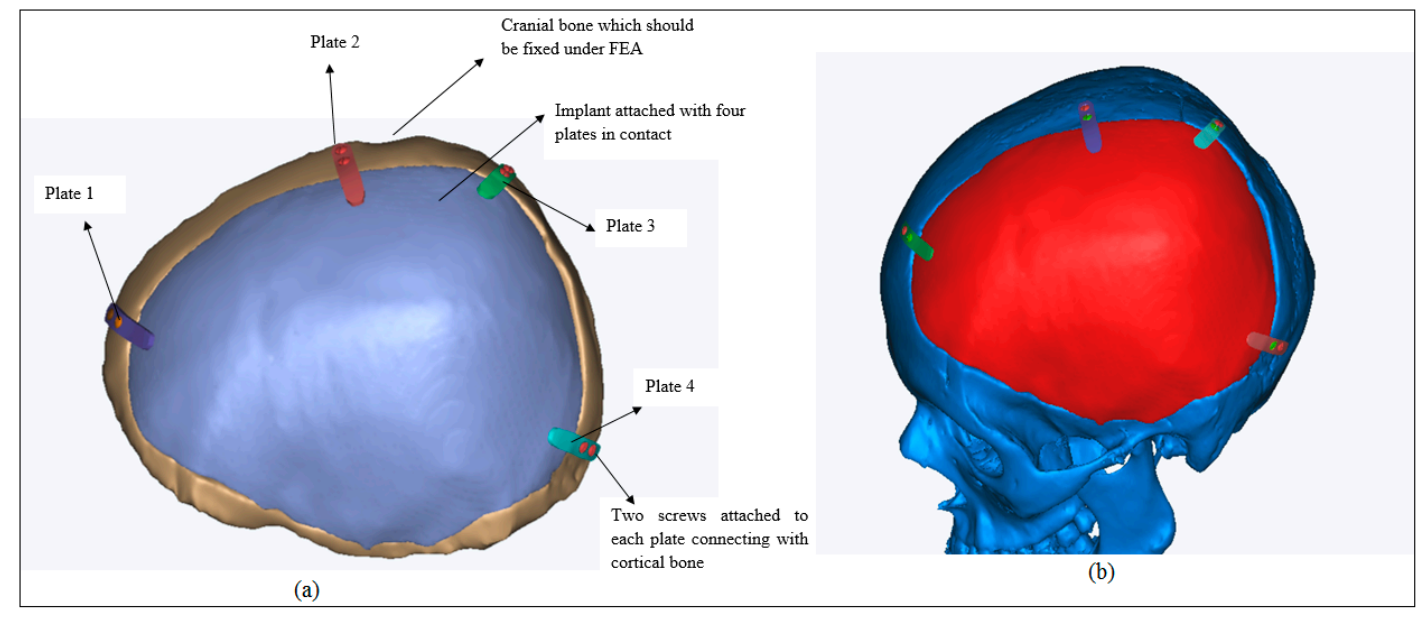

Figure 6. (a) Cranial implant with fixation plates; (b) Implant fixed on the prototype.

The FEA model was created to assess the biomechanical stability of the designed custom cranial implant [31]. The pre-processing, post-processing and the execution of the developed FEA model were performed in the Abaqus software. The properties of materials designated to the FEA model are presented in Table 1 . The different material properties were assigned to different regions on the skull [32]. The attributes of cortical bone were designated to the cranium, while Ti6Al4V ELI was assigned to the customized cranial implant [33,34].

Table 1. Properties of materials utilized in FEA model [18,35].

\begin{tabular}{cccc}
\hline Materials & Young's Modulus (MPa) & Poisson's Ratio & Yield Strength (MPa) \\
\hline $\begin{array}{c}\text { Cortical Bone } \\
\text { Cranial reconstruction }\end{array}$ & 13700 & 0.3 & 122 \\
plate, (Ti6Al4V ELI) & 120000 & 0.3 & 930 \\
\hline
\end{tabular}

Before analyzing the FEA model, the 3D model was fixed for minor geometrical errors, including the removal of very small faces and edges on both the implant and bone section. The skull (or the cortical bone section) was fixed at four positions at the bottom as shown in Figure 7a. A static force of $50 \mathrm{~N}$ was applied in the center region of the implant over an area of $550 \mathrm{~mm}^{2}$. Moreover, the mesh-independent fasteners were used to model the joining between the implant and bone section. It is an effective approach to define an explicit connection between two or more surfaces in the same manner with a spot weld or rivet joint. Four fasteners were utilized at selected reference positions. The continuum tetrahedral quadratic elements with ten nodes (C3D10) were selected for the model as shown in Figure $7 \mathrm{~b}$. To avoid mesh distortion and improve element quality, the fine mesh was generated resulting in a total of 280000 elements for the implant and bone section. The ABAQUS/STANDARD was selected as the finite element solver with static general procedure. To ensure mesh-independent results, a finer mesh model was developed and checked with the original one.

The results obtained after executing the FEA model can be realized in Figure 8. The Von Mises stress distribution is shown in Figure 8a and the maximum value was around 2.5 MPa which was well below the Yield strength (930 MPa) of the titanium alloy (Ti6Al4V ELI) thus ensuring the absence of any plastic deformation in the implant. Moreover, the maximum principal strain distributions in Figure $8 \mathbf{b}$ marked comparatively high strained regions around fasteners and load areas. However, the overall strain levels were very low and the maximum value was around $1.49 \times 10^{-4}$. Similarly, Figure $8 \mathrm{c}$ shows the deformation pattern in the implant due to the applied load. As expected, maximum deformation occurred at the load area, however, the magnitudes were very low i.e., around $3.26 \times 10^{-6} \mathrm{~mm}$. In conclusion, the results showed that the implant design could be used satisfactorily for the replacement of the defected skull region. 


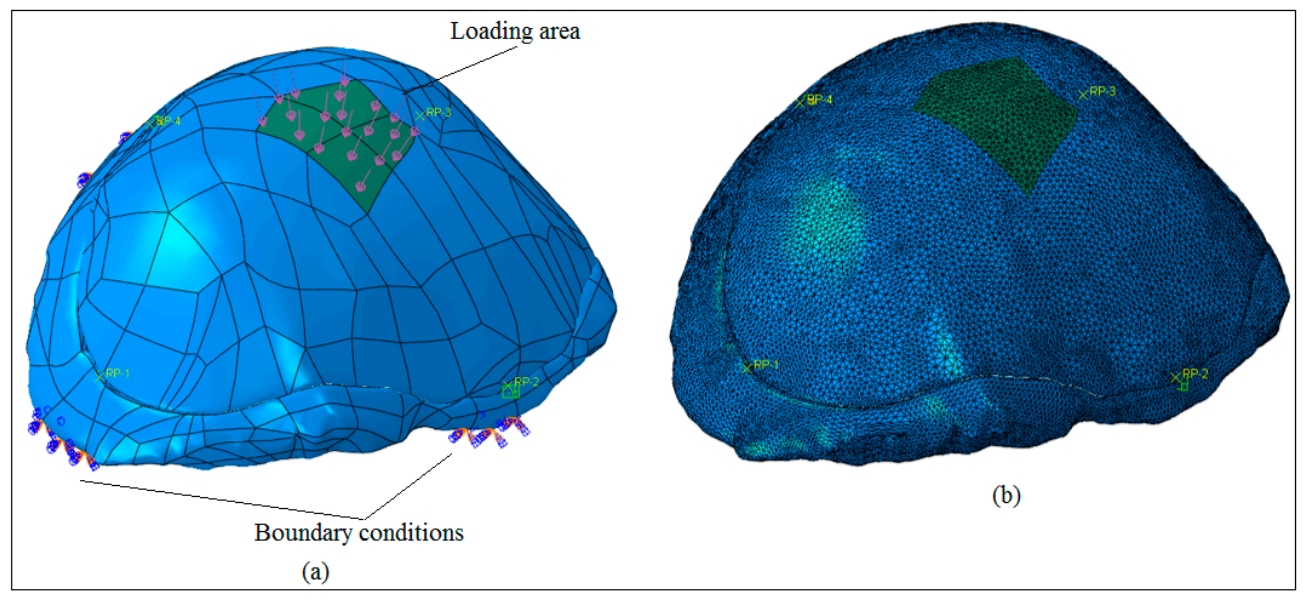

Figure 7. (a) Loading area and boundary conditions; (b) Mesh generation.

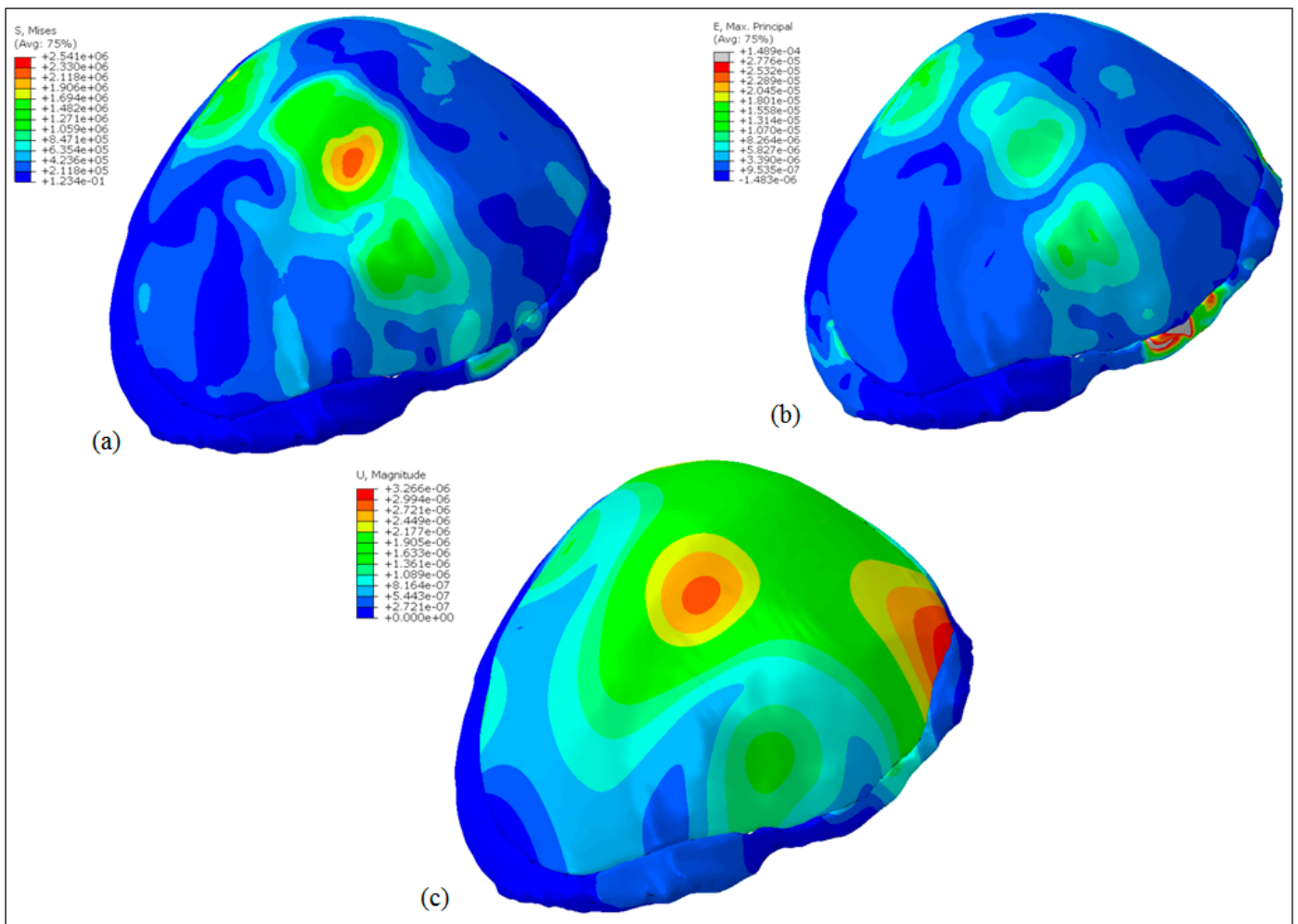

Figure 8. FEA Results illustrating: (a) stress distribution; (b) strain distribution; (c) maximum displacement.

The fabrication of the cranial implants was preceded by the elimination of errors in the STL file as described in Figure S1. The errors such as overlapping, intersecting triangles, bad edges, and other defects were resolved in Magics ${ }^{\circledR}$. The purpose of this stage was the processing of the STL file and determining the best position and orientation for fabrication.

Once the STL models were flawless, appropriate supports were generated on the overhanging structures as shown in Figure S2. The most suitable supports were essential to precisely build the prototype without any aberration. The support also helped in the straightforward ejection of the prototype from the building table. The support structures were also required for efficient heat transfer to minimize any distortion and to facilitate the fabrication of overhanging parts. Moreover, the support structures were attached to the cranial implant with teeth at the top and bottom for their easy removal. 


\subsection{Fabrication}

The fabrication of the customized cranial implant and dog bone shaped specimens were carried out in this phase. The dog bone shaped specimens were needed to assess the tensile strength of the tailor-made cranial implant. The custom made cranial implant as a result of its aberrant and unsteady structure could not be analyzed with any standard mechanical testing. Moreover, there was no conclusive standard which could be employed to perform the tensile test on the customized cranial implant. Henceforth, to investigate the tensile strength of Ti6Al4V ELI material used in cranial implant, dog bone shaped specimens as per ASTM E-8 standards were designed. Certainly, several previous works can be pointed out which have also performed similar studies on titanium specimens to estimate their mechanical properties $[33,36,37]$. There are also shreds of evidence in the literature, where dog bone shaped specimens were analyzed instead of real shapes in order to comprehend the tensile properties of a particular material. For example, Komurlu et al. [38] recommended a dog bone shaped specimen as the ideal geometry for estimating accurate tensile results of different rock materials. The dog bone shaped specimen used in this study possessed an overall length of $100 \mathrm{~mm}$, a gauge length of $25 \mathrm{~mm}$ and a width of $6 \mathrm{~mm}$ as depicted in Figure S3. The dog-bone structure was manufactured as per ASTM E-8/E-8M/16a standard [39,40].

The particle size analysis as shown in Figure 9a revealed that the titanium powder (Ti6Al4V ELI) with the particle size between $50-100 \mu \mathrm{m}$ was utilized for the fabrication of the customized cranial implant and the dog bone specimen in this study. Figure $9 \mathrm{~b}$ represents the analysis of Ti6Al4V ELI powder using JOEL's JSM-6610LV (JOEL, United States) Scanning Electron Microscope (SEM). The formation of the powder particles was primarily spherical in shape with slight variation in geometry. The chemical composition of Ti6Al4V Extra-low interstitial (ELI) as revealed in Figure 9c was $6.04 \%$ Aluminum (Al), 4.05\% Vanadium (V), 0.013\% Carbon (C), 0.0107\% Iron (Fe), and $0.13 \%$ Oxygen $(\mathrm{O})$, with the remaining constituent as Titanium (Ti) in weight percent.

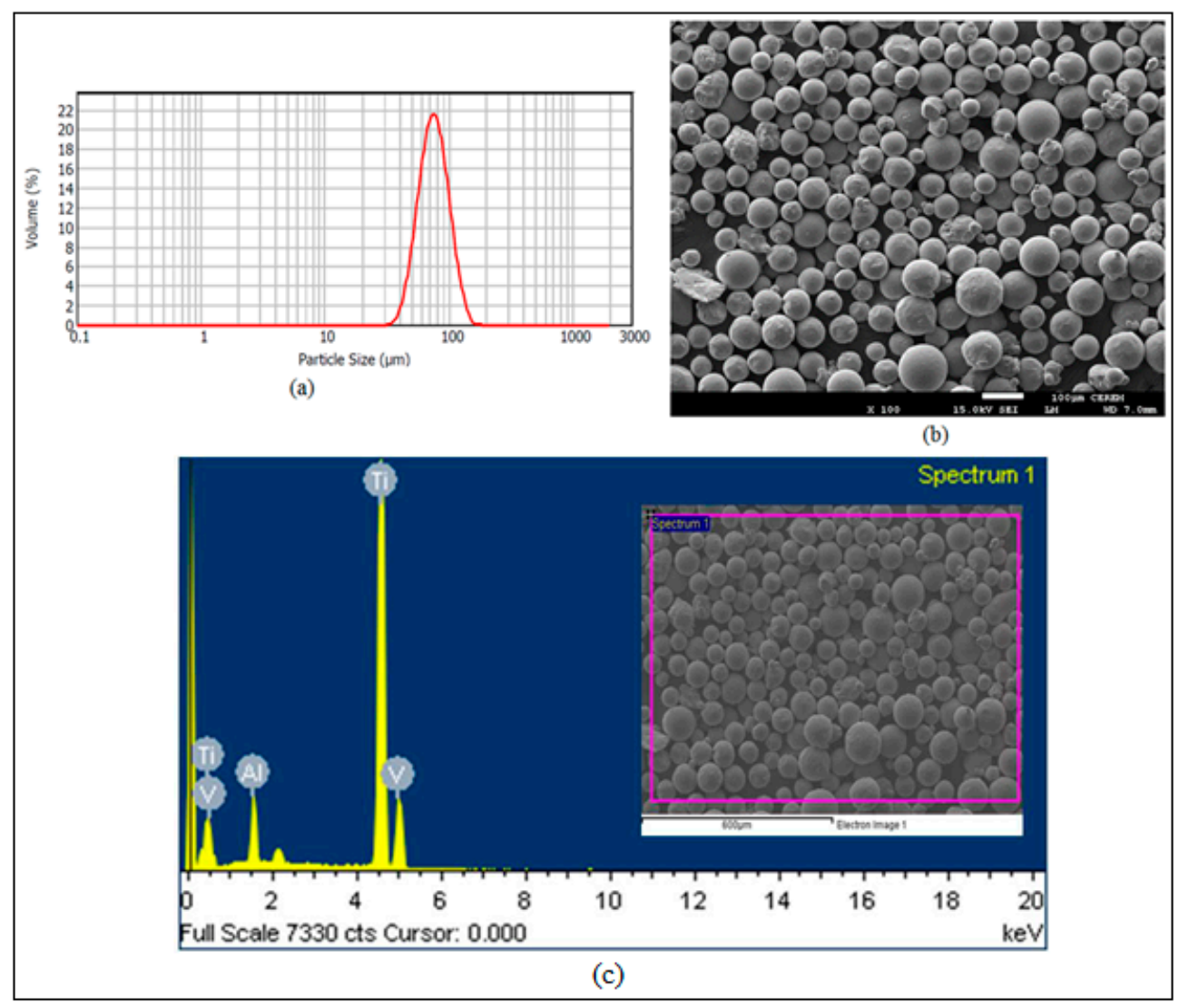

Figure 9. Ti6Al4V ELI: (a) particle size distribution; (b) SEM image; (c) material composition. 
The ARCAM's EBM machine as shown in Figure 10 was employed for the fabrication. The fabrication in the EBM process consisted of three primary stages: (1) preheating of the metal powder, (2) scanning as well as melting of the powder and (3) lowering of the building platform along with the raking of the powder bed. At the outset, the entire Ti powder layer in the powder bed was warmed up (or preheated) through scanning at a high scan speed until the certain intended temperature $\left(730^{\circ} \mathrm{C}\right)$ was reached. The preheating was carried out at eighty percent of the melting temperature in order to fuse the powder particles. The preheating also aided in reducing the stresses and sintering the unbound powder particles for the retention of the consecutive powder layers. The standard ARCAM parameters, preheat-I and preheat-II were utilized during fabrication. In preheat-I, the complete powder bed was scanned and in preheat-II, the scanning was executed only in the melting region. Subsequently, a high-velocity beam of electrons scanned the metal powder line by line according to the defined CAD geometry through various lenses. The scanning and melting operation consisted of two processes, contouring and infill hatching. First, the contours were melted by using electron beams, depending on the boundary representation (or the cross-section) of the 2D slices. However, the beam current and the scan speed were raised in hatching in contrast to contouring. In order to melt and fill the area between the contours, the powder layers were screened using a snaking melt strategy in the back and forth direction. The metal powder in the contours and the hatching part was melted, leaving the rest of the powder for recycling. After the preheating and melting of the particular layer, the build platform was descended through one layer thickness $(50 \mu \mathrm{m})$ and a fresh powder layer was supplied from hoppers and spread uniformly onto the formerly solidified layer with the help of raking blades. These three stages were reciprocated in a cycle manner until the 3D physical part was obtained.

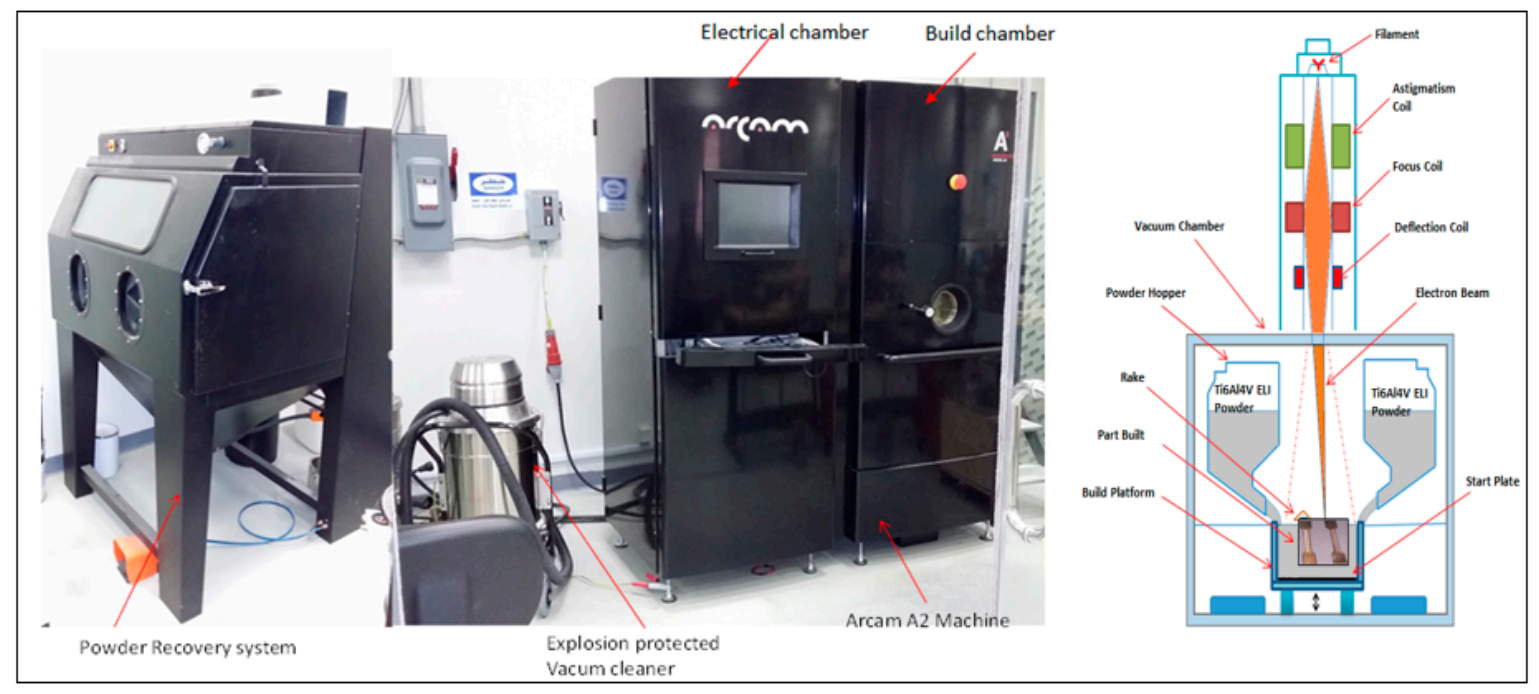

Figure 10. ARCAM A ${ }^{2}$ set up and schematics of EBM.

The produced EBM specimens were finally blown in a powder recovery system (PRS) using a high-pressurized air nozzle for taking out the finely trapped powder particles. The support structures (Figure 11b) attached to the cranial implant (Figure 11a) were removed manually using plyers and this procedure did not result in any defect on the fabricated specimen. The fabricated customized cranial implant after support removal (Figure 11c,d) did not show any sign of burr or protrusion (Figure 11e) on its surface. The titanium cranial implant was finally tested on the polymer skull model (Figure 11f) for fitting evaluation. The EBM produced as-built titanium cranial implant does not require any post-processing treatment, as its surface finish is ideal for osseointegration (bone-ingrowth) [41]. Indeed, several prior studies had established that there was no significant improvement in the adhesion or osseointegration with post-processing. An in-vivo study on rabbits using EBM produced Ti6Al4V implants exhibited similar surface chemical composition and surface roughness in contrast to wrought 
Ti6Al4V and machined Ti6Al4V implants [42]. Similarly, Biemond et al. observed that the presence of coating or surface treatment of EBM fabricated implant did not result in enhanced bone in-growth or mechanical fixation strength in comparison to the as-built EBM specimen [43]. Based on these earlier investigations, it can be inferred that the as-built EBM specimen does not require any post surface treatment if its surface roughness lies within the specified range of the EBM manufacturer. According to ARCAM, the surface roughness ( $\mathrm{Ra}$ ) of the as-built specimen should fall within the interval of 25-35 $\mu \mathrm{m}$ [44]. Henceforth, the surface roughness of the fabricated cranial implant in this study was also measured $(\mathrm{Ra}=25.3 \mu \mathrm{m})$ and found within the specified range. However, if needed, the EBM built cranial implant can be post-processed for better surface finish using plasma electro polishing [45] and laser ablation techniques $[46,47]$.
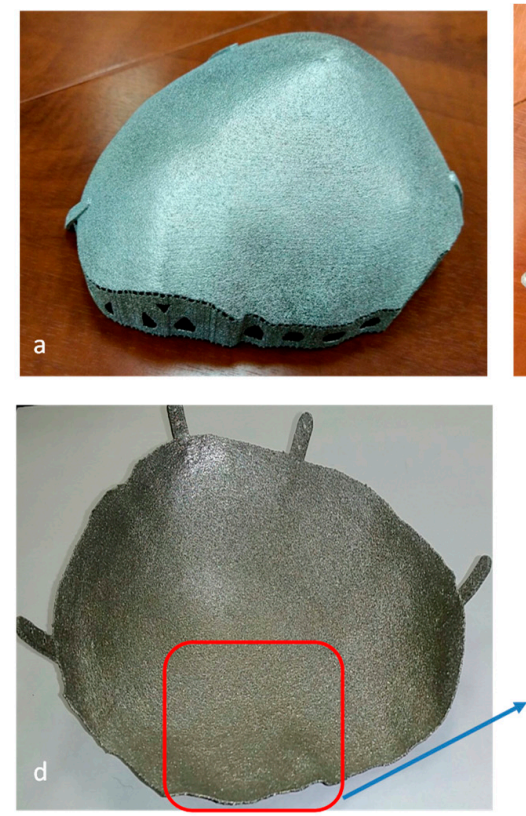
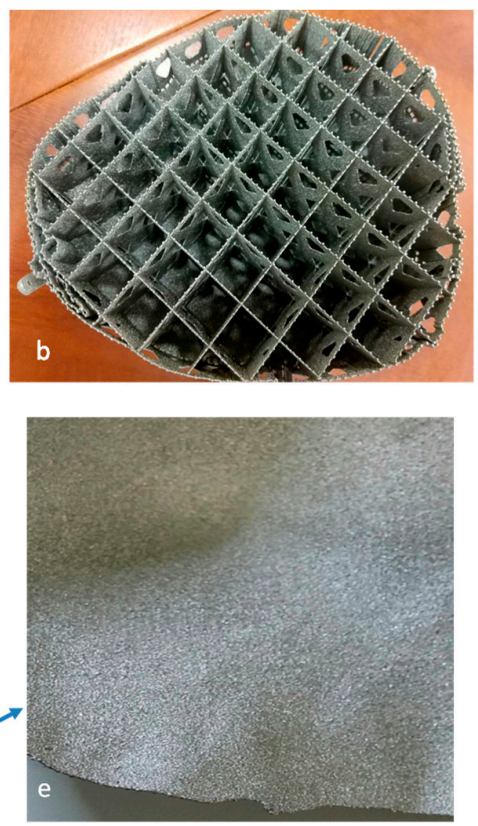
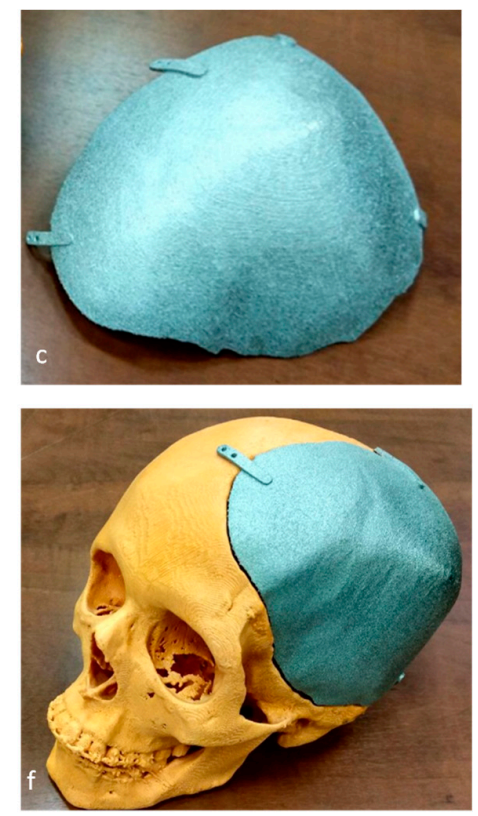

Figure 11. EBM Fabricated parts: (a) Top view of titanium cranial implant with supports; (b) Bottom view showing support structures; (c) Top view of cranial implant after support removal; (d) bottom view after support removal; (e) Enlarged view illustrating no burr or protrusion and (f) Cranial implant fitting rehearsal on a polymer skull model.

\subsection{Testing and Validation}

In this phase of testing and validation, the custom designed cranial implant was assessed for accuracy, appearance, and aesthetics in addition to the intrinsic investigation of the implant for tensile strength, hardness and material composition. This phase has been discussed in detail in the subsequent sections.

\section{Analysis Results}

The accuracy of the fabricated cranial implant was estimated by employing a 3D comparison analysis in Geomagics Control ${ }^{\circledR}[48]$. It can be assumed as one of the comprehensive and dynamic techniques to graphically estimate the surface deviations between the actual object and the reference CAD model [49]. As shown in Figure 12a, the custom made cranial implant was mounted and fixed on the skull and digitized to acquire the test data. The scanning was performed by employing the laser scanner on the Faro Platinum arm (FARO, Florida, USA). The visual investigation on the actual part in conjunction with the visualization of the captured point data (Figure 12b) revealed satisfactory appearance, aesthetics and a near perfect outer profile on the defective side of the skull when the implant was mounted on the cranium prototype. 


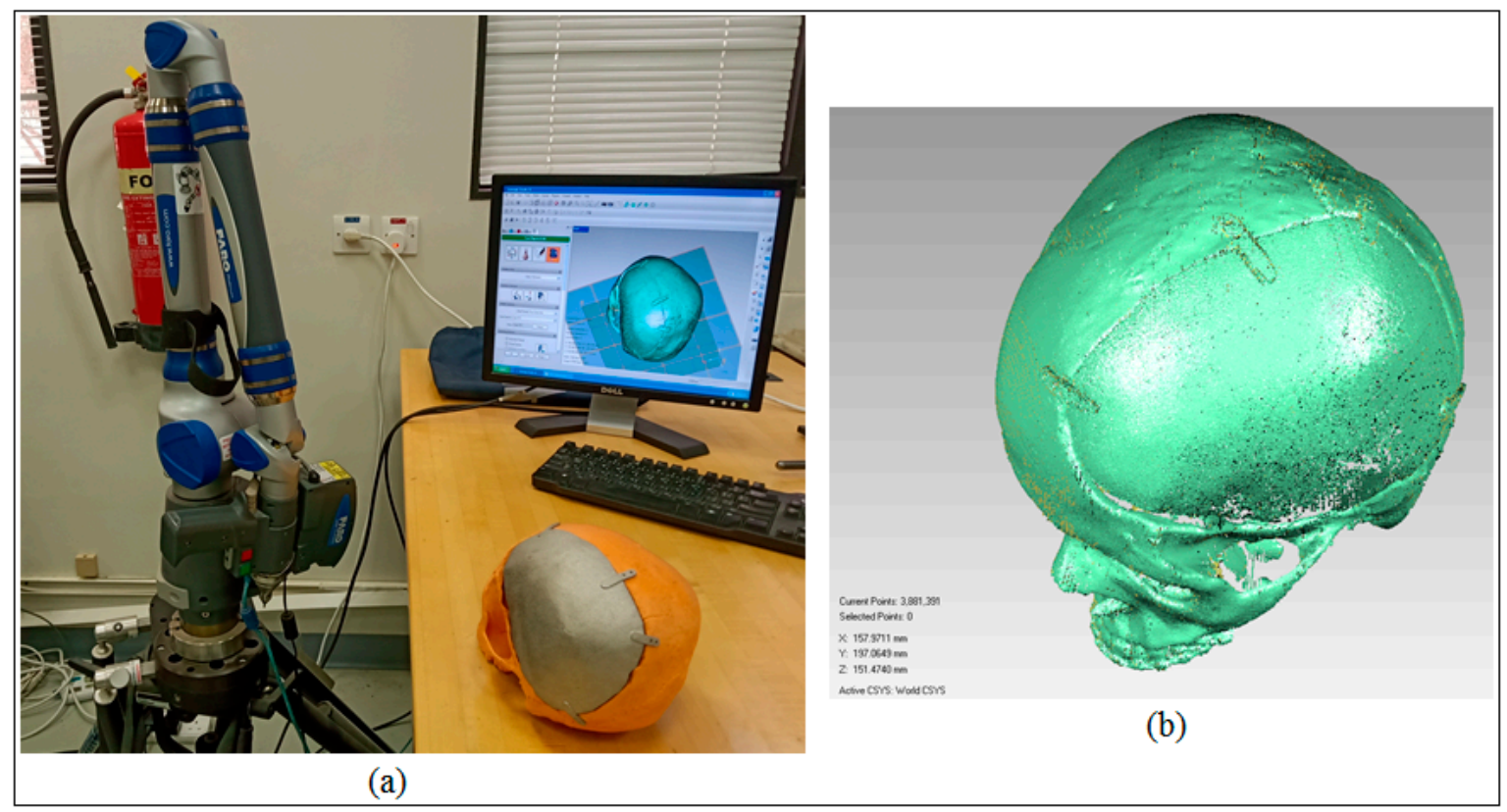

Figure 12. (a) Data acquisition using Faro Platinum arm; (b) Digitized point cloud data.

The 3D comparison analysis commenced with the definition of the test object and the reference CAD model. To digitize the test data, the outer surface of the remodeled skull (or the skull mounted with implant) was scanned and imported as an STL model in Geomagics Control ${ }^{\circledR}$. The outer surface was investigated, since the customized cranial implant was designed depending on the outer profile of the skull. The reference CAD model was obtained by taking out the defect and improvising (or mirroring) the healthy side on it. This CAD model obtained using the mirroring technique was used as a reference because it could satisfactorily represent the ideal anatomy [29,30]. Subsequently, the 3D comparison analysis was performed to determine the accuracy of the remodeled skull. The test data (acquired point cloud) as shown in Figure $12 \mathrm{~b}$ was then aligned with the reference CAD model using the best fit alignment procedure. The best fit alignment was significant to ensure that both the test and reference objects were positioned in the same coordinate system. The statistics used to quantify the accuracy of the implant on the skull were the average deviation in the positive and negative directions as well as the root mean square (RMS). The RMS value (i.e., the square root of the average of squared errors) provided the overall accuracy for the remodeled skull. The average deviation statistics were selected because they report the average variations, thereby approximating the difference between the remodeled skull with the customized implant and the original skull of the patient in the outward and inward directions.

The outcome of the 3D deviation analysis has been represented graphically in Figure 13. When the remodeled or reconstructed skull was analyzed with the mirrored cranium, the average deviation was in the range of $0.9294 \mathrm{~mm}$ in the outside direction and $-1.0587 \mathrm{~mm}$ in the inward of the skull. Based on average deviation and RMS $(1.5347 \mathrm{~mm})$ values, the author inferred that the reconstructed skull was acceptable and it provided satisfactory aesthetics and appearance. 


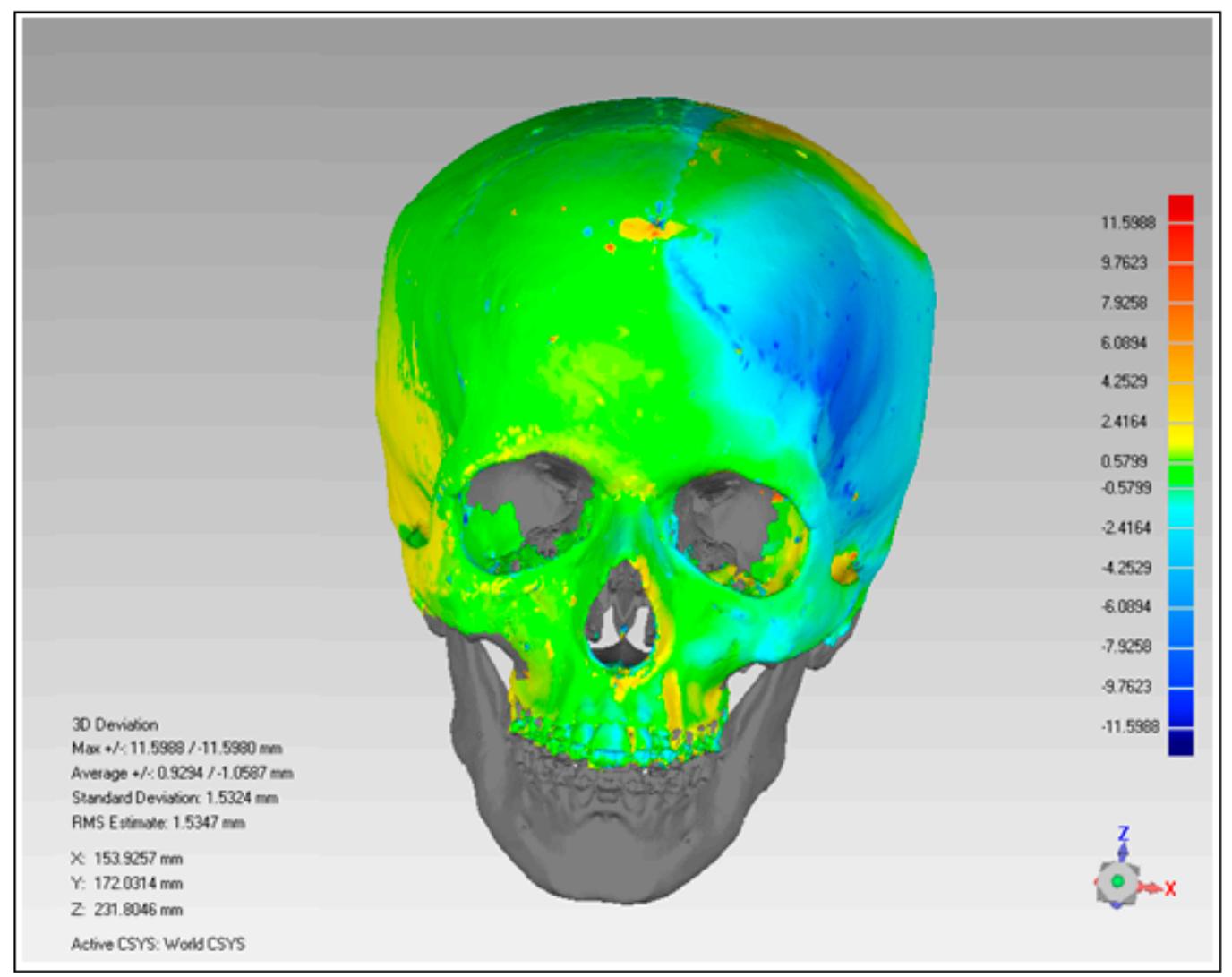

Figure 13. Outcome from 3D comparison analysis.

To analyze the tensile strength, the EBM produced dog bone specimens $(n=5)$ as shown in Figure 14a were subjected to an axial tensile test. The tensile test was carried out using an Instron universal testing machine (5984 30 K, UTM-USA) as illustrated in Figure 14b. The load and displacement data were regularly observed and noted. A constant displacement speed was maintained and its load and elongation were measured to test the tensile durability of the EBM built specimens. The strains were measured using strain gauge which was glued onto the specimens. The state-of-the-art built-in control platform Blue hill 3 was used to define, program, and perform the novel tests. Figure $14 \mathrm{c}$ illustrates the EBM test samples before and after the tensile test. The stress-strain relationship of the EBM dog bone specimens was calculated and plotted as shown in Figure 14d. The average yield and tensile strength of the specimens were determined from the stress-strain curves. The average yield and tensile strength for the EBM specimen were found to be $825 \mathrm{MPa}$ and $880 \mathrm{MPa}$ respectively from the tensile test. These values were better than the average yield (795 MPa) and tensile strength $(860 \mathrm{MPa})$ required for Ti6Al4V ELI specimen [33]. Moreover, these mechanical results were similar and in accordance with the values as reported by other researchers [37,50]. The calculated yield and tensile strength in the current study were higher than the required yield and tensile strength as per the ASTM standard [33,51]. This suggested that the EBM produced cranial implant possessed the required mechanical strength that is needed in medical applications. 


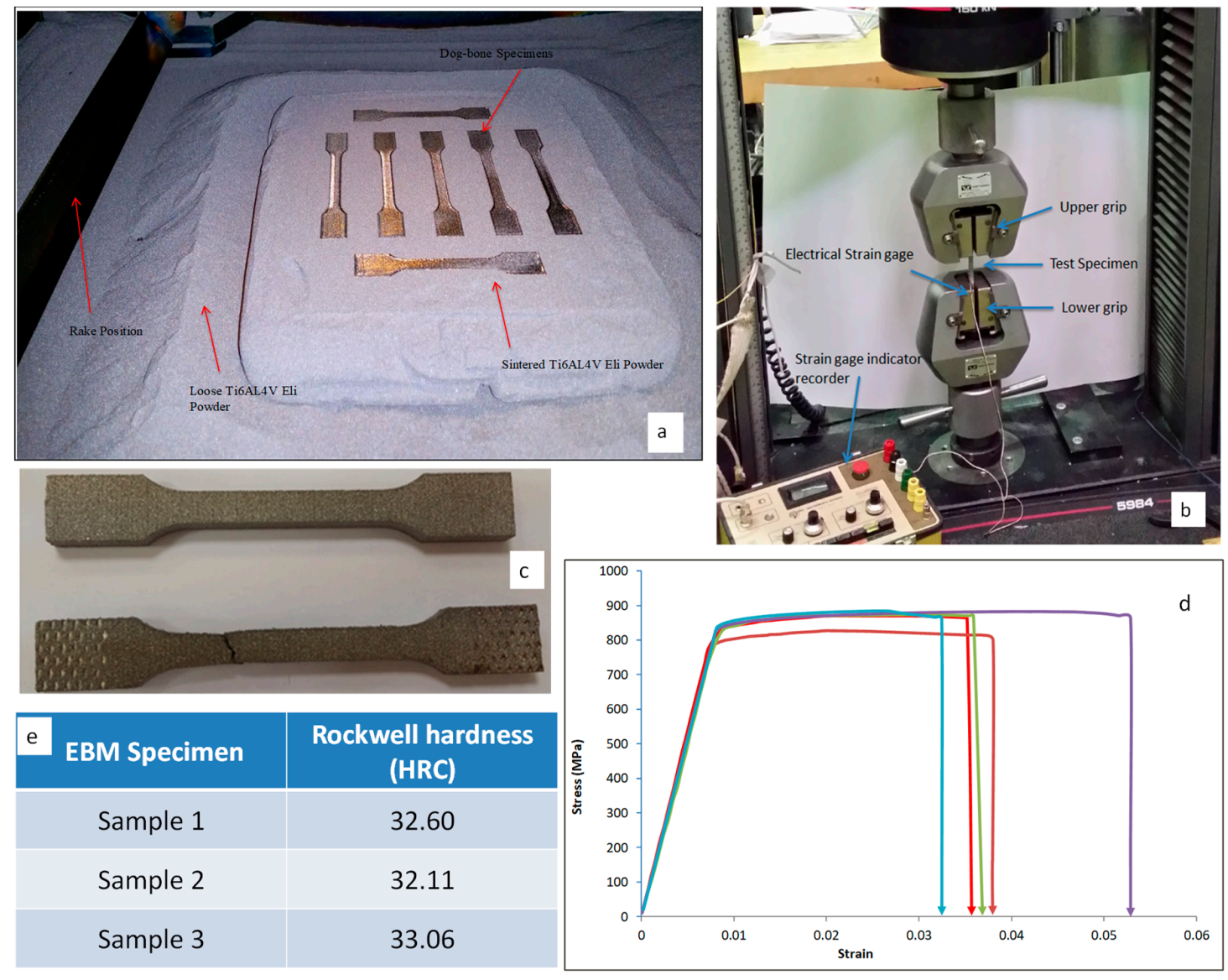

Figure 14. (a) EBM produced dog bone shaped specimen; (b) Tensile test on an Instron 2716 series machine; (c) EBM produced titanium tensile specimens before and after the test; (d) Tensile stress-strain relationship curve for test specimens and (e) Rockwell hardness measurement (HRC) results.

Similarly, the surface hardness (or the resistance to deformation) of the EBM built specimen were determined by employing Rockwell hardness test (HRC) using WOLPERT UH930 (USA) universal hardness tester (Figure S4). The Rockwell C scale is usually abbreviated HRC (Hardness Rockwell C). The indentation was generated using a cone diamond indenter with a load of $150 \mathrm{kgf}(1.5 \mathrm{KN})$ for 3-5 s. Three arbitrary regions were identified on the top surface of three EBM built specimens and a mean value of nine measurements was computed for hardness. Each of the indentations was measured at a distance of $5 \mathrm{~mm}$ from the previous indentation. The surface hardness value of the Ti6Al4V ELI specimen was in the range of 30-35 HRC (Figure 14e), which was consistent with the required ARCAM and ASTM standards [33]. Notice that the computed values of strength and hardness can further be justified through multiple studies that have investigated the mechanical properties of EBM fabricated Ti6Al4V ELI specimen. Their studies also reported ultimate strength in the range of 775 to $1150 \mathrm{MPa}$ and surface hardness in the range of 30 to 35 HRC $[52,53]$.

The consequent surface and elemental analysis of the EBM built specimen was also performed by employing JOEL JSM-6610LV SEM along with the attached energy dispersive X-ray spectroscopy (EDX). The EDX analysis was conducted to analyze the material composition in Ti6Al4V ELI post EBM fabrication. As shown in Figure 15, the Ti peak was higher than the $\mathrm{Al}$ and $\mathrm{V}$, as anticipated. The general composition of the specimen was measured as follows: $6.24 \% \mathrm{Al}$. $3.89 \% \mathrm{~V}$ and $89.87 \% \mathrm{Ti}$ in weight percent. Based on the composition results, it can be inferred that the chemical composition of the fabricated EBM specimen did not vary considerably from the initial composition of the raw material (Figure 9c). 


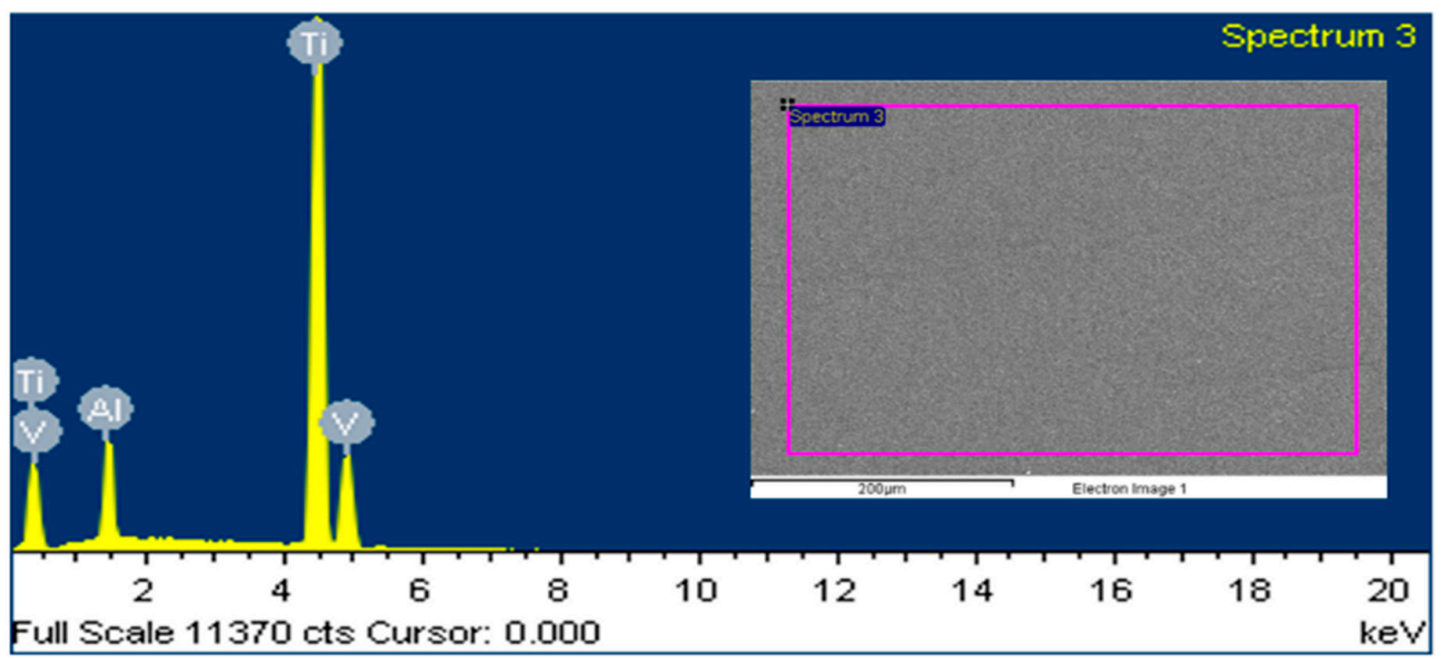

Figure 15. EDX Spectrum and SEM image of EBM produced Ti6Al4V ELI part.

To compute the weight of the substituted cranial bone, the density formulae were utilized in which volume was taken from the Magics ${ }^{\circledR}$ software (Materialise, Belgium). The density was assumed to be $1600 \mathrm{~kg} / \mathrm{m}^{3}$ [54]. The weights of the EBM fabricated titanium cranial implant was measured using a digital weighing scale. The results as shown in Table 2 inferred that the weight of the EBM fabricated titanium cranial implant was a closer match to the substituted defected bone portion. Hence, EBM produced titanium implant will not have any stress shielding effect on the neighboring cranial bone tissue.

Table 2. Weight details of the replaced cranial bone and EBM fabricated titanium implant.

\begin{tabular}{ccc}
\hline Material & Volume $\left(\mathbf{m m}^{\mathbf{3}}\right)$ & Weight (grams) \\
\hline Replaced Cranial Bone & 84427 & 135 \\
\hline Titanium implant & 33277 & 128 \\
\hline
\end{tabular}

\section{Conclusions}

The realization of cranial reconstruction significantly depends on the restoration of its appearance, aesthetics and mechanical properties. It has been a known fact that the traditional methods of cranial reconstruction are insufficient because they cannot successfully address customization. Therefore, an effective methodology has been developed in the pursuit of a customized, pleasing and reliable cranial implant. The EBM technology has been integrated with CT to accomplish the objective of a customized implant. Certainly, the remarkable features of this methodology were its four pillars, including image processing, modeling, fabrication, and testing. Generally, the difficult task in customized reconstruction, especially using AM is the specification of its approval tests. Therefore, in this work, several validation techniques have been utilized to ascertain the quality of the implant produced by the EBM. For instance, the 3D comparison analysis was utilized to determine the accuracy and fitting of the implant, the tensile test was employed to confirm the mechanical strength, FEA to verify its load resistance ability, etc. The implemented approach was unique and exhaustive as it intended to minimize uncertainty in each phase through techniques such as STL error correction, thickness reduction, etc. The segmentation approach was employed to slice the defective region, while the mirror reconstruction technique was applied to acquire the customized implant for the affected region. The results of the 3D comparison analysis established that the anatomy or the outer profile of the skull were dependable in terms of appearance, fitting and aesthetics. The average deviation lied within the range of -1.0587 to $0.9294 \mathrm{~mm}$, along with the RMS value of $1.5347 \mathrm{~mm}$. These results also affirmed the mirror modeling technique as an ideal approach to reconstruct defects that exist on one side (left or right) of the head (imagine a plane 
running from head to tail leading to bilateral symmetry). Moreover, to minimize the shielding effect, the implant fabricated by the EBM was processed to achieve a thickness in the range of $\simeq 1.76-2 \mathrm{~mm}$. The FEA analysis was imperative to ascertain the loading ability of the designed customized implant. This analysis based on maximum stress $(2.5 \mathrm{MPa})$, strain value $\left(1.49 \times 10^{-4}\right)$ and maximum deformation $\left(3.26 \times 10^{-6} \mathrm{~mm}\right)$ deduced that the accomplished implant design can be employed convincingly in the restoration of the unhealthy skull region.

The analysis results post-fabrication were also adequate as acknowledged by various mechanical test procedures. The average yield $(825 \mathrm{MPa})$ and the tensile strength $(880 \mathrm{MPa})$ of the EBM fabricated specimens were in agreement with the previous researches as well as the ASTM standards in the medical industry. Similarly, the surface hardness of these specimens was in the range of 30-35 HRC, which was consistent with the desired ARCAM and ASTM norms. The chemical composition of the manufactured specimen also did not alter appreciably in comparison to its raw state, thus validating its intactness. Besides, the weight of the EBM fabricated titanium cranial implant was in complete agreement with that of the substituted skull region.

The employed approach is effective and useful because it can successfully minimize the revisions and errors, enhance fit and result in implant stability as well as reduce the treatment time and operative difficulties. The EBM produced cranial implant augments the aesthetic and functional recovery of cranium abnormalities to accomplish efficient and immediate reconstruction. The proposed method of custom designed cranial implant can be integrated with more facets of bone surgeries where reconstruction plates are applied. Certainly, the existing available techniques cannot confirm all of the growing customization needs, so attempts to develop a more appropriate mode of reconstruction should persist in the future. Therefore, the authors would like to extend this work by employing a new modeling technique and utilizing more tests, such as a fatigue test, validation of compressive strength, etc.

Supplementary Materials: The following are available online at http:/www.mdpi.com/2076-3417/9/12/2513/s1, Figure S1: STL corrections performed on the cranial implant design, Figure S2: Generated supports on cranial implant, Figure S3: Dog bone shaped specimen to evaluate the tensile strength [39,40], Figure S4: Rockwell hardness (HRC) test on EBM fabricated specimens.

Author Contributions: K.M. conceived and designed the experiments; K.M. \& S.H.M. performed the experiments; U.U. helped in the analysis; H.A. analyzed the data; K.M. \& S.H.M. wrote and reviewed the paper.

Funding: This research was financially supported by Deanship of Scientific Research, King Saud University: Research group No. RG-1440-034.

Acknowledgments: The authors extend their appreciation to the Deanship of Scientific Research at King Saud University for funding this work through Research group no RG-1440-034.

Conflicts of Interest: The authors declare no conflict of interest.

\section{References}

1. Saldarriaga, J.F.I.; Vélez, S.C.; Posada, M.D.A.C.; Henao, I.E.B.B.; Valencia, M.E.C.A.T. Design and Manufacturing of a Custom Skull Implant. Am. J. Eng. Appl. Sci. 2011, 4, 169-174. [CrossRef]

2. Joffe, J.M.; Nicoll, S.R.; Richards, R.; Linney, A.D.; Harris, M. Validation of computer-assisted manufacture of titanium plates for cranioplasty. Int. J. Oral Maxillofac. Surg. 1999, 28, 309-313. [CrossRef]

3. Pompili, A.; Caroli, F.; Carpanese, L.; Caterino, M.; Raus, L.; Sestili, G.; Occhipinti, E. Cranioplasty performed with a new osteoconductive osteoinducing hydroxyapatite-derived material. J. Neurosurg. 1998, 89, $236-242$. [CrossRef] [PubMed]

4. Jardini, A.L.; Larosa, M.A.; Filho, R.M.; Zavaglia, C.A.C.; Luis Fernando Bernardes, L.F.; Lambert, C.S.; Calderoni, D.R.; Kharmandayan, P. Cranial reconstruction: 3D biomodel and custom-built implant created using additive manufacturing. J. Cranio Maxillofac. Surg. 2014, 42, 1877-1884. [CrossRef] [PubMed]

5. Chen, X.; Xu, L.; Li, X.; Egger, J. Computer-aided implant design for the restoration of cranial defects. Sci. Rep. 2017, 7, 4199. [CrossRef] [PubMed]

6. Cantini, R.; Burchianti, M.; Lutzemberger, L.; Massei, A.; Ubiglia, G.P. Repair of skull defects by autogenous bone grafts. Child's Nerv. Syst. 1985, 1, 279-281. [CrossRef] 
7. Worm, P.V.; Ferreira, N.P.; Finger, G.; Collares, M.V. Autologous cranial bone graft use for trepanation reconstruction. J Cranio Maxillofac. Surg. 2015, 43, 1781-1784. [CrossRef]

8. Carr, B.C.; Goswami, T. Knee implants-Review of models and biomechanics. Mater. Des. 2009, 30, $398-413$. [CrossRef]

9. Hermawan, H.; Ramdan, D.; Djuansjah, J.R.P. Metals for Biomedical Applications. In Biomedical Engineering_From Theory to Applications; Fazel, R., Ed.; InTech: London, UK, 2011. [CrossRef]

10. Avraham, T.; Franco, P.; Brecht, L.E.; Ceradini, D.J.; Saadeh, P.B.; Hirsch, D.L.; Levine, J.P. Functional outcomes of virtually planned free fibula flap reconstruction of the mandible. Plast. Reconstr. Surg. 2014, 134, 628-634. [CrossRef]

11. Samman, N.; Luk, W.K.; Chow, T.W.; Cheung, L.K.; Tideman, H.; Clark, R.K. Custom-made titanium mandibular reconstruction tray. Aust. Dent. J. 1999, 44, 195-199. [CrossRef]

12. Bhargava, D.; Bartlett, P.; Russell, J.; Liddington, M.; Tyagi, A.; Chumas, P. Construction of titanium cranioplasty plate using craniectomy bone flap as template. Acta Neurochir. 2010, 152, 173-176. [CrossRef] [PubMed]

13. Yan, R.; Luo, D.; Huang, H.; Li, R.; Yu, N.; Liu, C.; Hu, M.; Rong, Q. Electron beam melting in the fabrication of three-dimensional mesh titanium mandibular prosthesis scaffold. Sci. Rep. 2018, 8, 750. [CrossRef] [PubMed]

14. Singare, S.; Lian, Q.; Wang, W.P.; Wang, J.; Liu, Y.; Li, D.; Lu, B. Rapid prototyping assisted surgery planning and custom implant design. Rapid Prototyp. J. 2009, 15, 19-23. [CrossRef]

15. Bioimplants: Scitechstory. Tracking the Impact of Science and Technology. Body implants. Available online: http://scitechstory.com/impact-areas/body-implants/ (accessed on 2 November 2013).

16. Niinomi, M. Mechanical properties of biomedical titanium alloys. Mater. Sci. Eng. A 1998, 243, $231-236$. [CrossRef]

17. Rajnesh, T. Processing Techniques and Tribological Behavior of Composite Materials; IGI Global: Hershey, PA, USA, 2015.

18. Kulkarni, M.; Mazare, A.; Schmuki, P.; Iglic, A. Biomaterial Surface Modification of Titanium and Titanium Alloys for Medical Applications. Nanomedicine; One Central Press: Altrincham, UK, 2014; pp. 111-136.

19. Khan, S.F.; Dalgarno, K.W. Design of Customized Medical Implants by Layered Manufacturing; School of Mechanical and Systems Engineering, NC University: Raleigh, NC, UK, 2009.

20. Milovanovic, J.; Trajanovic, M. Medical applications of rapid prototyping. Mech. Eng. 2007, 5, 79 e85.

21. Al-Ahmari, A.; Ashfaq, A.; Mian, S.H.; Ameen, W. Evaluation of additive manufacturing technologies for dimensional and geometric accuracy. Int. J. Mater. Prod. Technol. 2019, 58, 129-154. [CrossRef]

22. FDA Clearance. Arcam: Arcam Announces FDA Clearance of Implants Produced with Additive Manufacturing. Available online: http://www.arcam.com/arcam-announces-fda-clearance-of-implantsproduced-with-additive-manufacturing/ (accessed on 10 September 2018).

23. A.B. Arcam: Electron Beam Melting EBM Process, Additive Manufacturing. Available online: http: //www.arcam.com/technology/electron-beam-melting/ (accessed on 17 February 2014).

24. Murr, L.E.; Gaytan, S.M.; Martinez, E.; Medina, F.; Wicker, R.B. Next Generation Orthopaedic Implants by Additive Manufacturing Using Electron Beam Melting. Int. J. Biomater. 2012, 2012, 14. [CrossRef] [PubMed]

25. Parthasarathy, J. 3D modeling, custom implants and its future perspectives in craniofacial surgery. Ann. Maxillofac Surg. 2014, 4, 9-18. [CrossRef] [PubMed]

26. Martin, M.P.; Olson, S. Post-operative complications with titanium mesh. J. Clin. Neurosci. 2009, 16, 1080-1081. [CrossRef] [PubMed]

27. Al Kindi, M.; Moiduddin, K.; Al-Ahmari, A.; Nasr, E.A.; Ramalingam, S. Functional and aesthetic outcomes of electron beam-melted titanium reconstruction plates: An in Vivo goat study. Biomed. Res. 2017, 28, 2073-2080.

28. Lee, J.W.; Fang, J.J.; Chang, L.R.; Yu, C.K. Mandibular Defect Reconstruction with the Help of Mirror Imaging Coupled with Laser Stereolithographic Modeling Technique. J. Formos. Med. Assoc. 2007, 106, 244-250. [CrossRef]

29. Arango-Ospina, M.; Cortés-Rodriguez, C.J. Engineering Design and Manufacturing of Custom Craniofacial Implants. In The 15th International Conference on Biomedical Engineering; Goh, J., Ed.; Springer International Publishing: New York, NY, USA, 2014; pp. 908-911. 
30. Zhou, L.B.; Shang, H.T.; He, L.S.; Bo, B.; Liu, G.C.; Liu, Y.P.; Zhao, J.L. Accurate Reconstruction of Discontinuous Mandible Using a Reverse Engineering/Computer-Aided Design/Rapid Prototyping Technique: A Preliminary Clinical Study. J. Oral Maxillofac. Surg. 2010, 68, 2115-2121. [CrossRef] [PubMed]

31. Ameen, W.; Al-Ahmari, A.; Mohammed, M.K.; Abdulhameed, O.; Umer, U.; Moiduddin, K. Design, finite element analysis (FEA), and fabrication of custom titanium alloy cranial implant using electron beam melting additive manufacturing. Adv. Prod. Eng. Manag. 2018, 13, 267-278. [CrossRef]

32. Al-Ahmari, A.; Nasr, E.A.; Moiduddin, K.; Anwar, S.; Al Kindi, M.; Kamrani, A. A comparative study on the customized design of mandibular reconstruction plates using finite element method. Adv. Mech. Eng. 2015, 7, 1-11. [CrossRef]

33. Arcam: Ti6Al4V ELI Titanium Alloy. Available online: http://www.arcam.com/wp-content/uploads/ArcamTi6Al4V-ELI-Titanium-Alloy.pdf (accessed on 17 February 2014).

34. El-Anwar, M.I.; Mohammed, M.S. Comparison between two low profile attachments for implant mandibular overdentures. J. Genet. Eng. Biotechnol. 2014, 12, 45-53. [CrossRef]

35. Wieding, J.; Jonitz, A.; Bader, R. The Effect of Structural Design on Mechanical Properties and Cellular Response of Additive Manufactured Titanium Scaffolds. Materials 2012, 5, 1336-1347. [CrossRef]

36. Mediaswanti, K.; Wen, C.; Ivanova, E.; Berndt, C.; Malherbe, F.; Pham, V.; Wang, J. A review on bioactive porous metallic biomaterials. J. Biomim. Biomater. Tissue Eng. 2013, 18, 1-8.

37. Khalid, R. Mechanical Property Evaluation of Ti-6al-4v Parts Made using Electron Beam Melting; University of Louisville: Louisville, KY, USA, 2007.

38. Komurlu, E.; Kesimal, A.; Demir, A.D. Dog bone shaped specimen testing method to evaluate tensile strength of rock materials. Geomech. Eng. 2017, 12, 883-898.

39. Assadi, H.; Schmidt, T.; Richter, H.; Kliemann, J.O.; Binder, K.; Gärtner, F.; Klassen, T.; Kreye, H. On Parameter Selection in Cold Spraying. J. Therm. Spray Technol. 2011, 20, 1161-1176. [CrossRef]

40. E28 Committee. n.d. Test Methods for Tension Testing of Metallic Materials. ASTM International. Available online: https://faculty.engr.utexas.edu/sites/default/files/astm_e8_08_0.pdf (accessed on 24 March 2019). [CrossRef]

41. Ek, R.K.; Hong, J.; Thor, A.; Bäckström, M.; Rännar, L.E. Micro- to Macroroughness of Additively Manufactured Titanium Implants in Terms of Coagulation and Contact Activation. Int. J. Oral Maxillofac. Implant. 2017, 32, 565-574.

42. Thomsen, P.; Malmström, J.; Emanuelsson, L.; René, M.; Snis, A. Electron beam-melted, free-form-fabricated titanium alloy implants: Material surface characterization and early bone response in rabbits. J. Biomed. Mater. Res. Part B Appl. Biomater. 2008, 90B, 35-44. [CrossRef] [PubMed]

43. Biemond, J.E.; Aquarius, R.; Verdonschot, N.; Buma, P. Frictional and bone ingrowth properties of engineered surface topographies produced by electron beam technology. Arch. Orthop. Trauma Surg. 2011, 131, 711-718. [CrossRef]

44. A. Arcam. Arcam A2 Machine Specification, ARCAM A2 TECHNICAL DATA, 2019. Available online: http://www.arcam.com/wp-content/uploads/Arcam-A2.pdf (accessed on 23 May 2019).

45. Zeidler, H.; Boettger-Hiller, F.; Edelmann, J.; Schubert, A. Surface Finish Machining of Medical Parts Using Plasma Electrolytic Polishing. Procedia CIRP 2016, 49, 83-87. [CrossRef]

46. Mohammad, A.; Mohammed, M.K.; Alahmari, A.M. Effect of laser ablation parameters on surface improvement of electron beam melted parts. Int. J. Adv. Manuf. Technol. 2016, 87, 1033-1044. [CrossRef]

47. Palmieri, F.L.; Watson, K.A.; Morales, G.; Williams, T.; Hicks, R.; Wohl, C.J.; Hopkins, J.W.; Connell, J.W. Laser Ablation Surface Preparation of Ti-6AL-4V for Adhesive Bonding, 2012. Available online: https: //ntrs.nasa.gov/archive/nasa/casi.ntrs.nasa.gov/20120009343.pdf (accessed on 19 October 2018).

48. Geomagic Control X, 3D Systems. Available online: https://www.3dsystems.com/software\#inspectionsoftware. (accessed on 10 February 2019).

49. Mian, S.H.; M. Mannan, M.A.; Al-Ahmari, A.M. The influence of surface topology on the quality of the point cloud data acquired with laser line scanning probe. Sens. Rev. 2014, 34, 255-265. [CrossRef]

50. Facchini, L.; Magalini, E.; Robotti, P.; Molinari, A. Microstructure and mechanical properties of Ti-6Al-4V produced by electron beam melting of pre-alloyed powders. Rapid Prototyp. J. 2009, 15, 171-178. [CrossRef]

51. Ti6AL4V ELI Tensile Strength: ASTM F136-13. Available online: http://www.astm.org/Standards/F136.htm (accessed on 3 January 2015). 
52. Benedetti, M.; Torresani, E.; Leoni, M.; Fontanari, V.; Bandini, M.; Pederzolli, C.; Potrich, C. The effect of post-sintering treatments on the fatigue and biological behavior of Ti-6Al-4V ELI parts made by selective laser melting. J. Mech. Behav. Biomed. Mater. 2017, 71, 95-306. [CrossRef]

53. Koike, M.; Greer, P.; Owen, K.; Lilly, G.; Murr, L.E.; Gaytan, S.M.; Martinez, E.; Okabe, T. Evaluation of titanium alloys fabricated using rapid prototyping technologies-Electron beam melting and laser beam melting. Materials 2011, 4, 1776-1792. [CrossRef]

54. Soh, C.K.; Yang, Y.; Bhalla, S. (Eds.) Smart Materials in Structural Health Monitoring, Control and Biomechanics; Springer: Berlin, Germany, 2012.

(C) 2019 by the authors. Licensee MDPI, Basel, Switzerland. This article is an open access article distributed under the terms and conditions of the Creative Commons Attribution (CC BY) license (http://creativecommons.org/licenses/by/4.0/). 